\title{
CDISC SDTM Terminology
}

National Cancer Institute

\section{Source}

National Cancer Institute. CDISC SDTM Terminology. NCI Thesaurus. Code C66830.

The terminology subset that includes terms pertaining to the CDISC Study Data

Tabulation Model (SDTM). 